\title{
Inter-Individuality and plant hormones
}

\author{
Tony Trewavas* \\ Institute of Molecular Plant Science, Kings Buildings, University of Edinburgh, Edinburgh EH9 3JH, Scotland
}

It is not common for papers on plant hormones to find their way into any endocrinological journals. Plants and mammals seem as far apart biologically as one could get. But in a number of respects animal and plant hormones do share some common issues in which knowledge in one can help better understanding of the other.

Plant hormones are organic chemicals that are synthesised either in response to environmental challenges or at discrete stages of the continuous process of plant development. They work at concentrations of $10^{-7} \mathrm{M}$ or lower. They help coordinate growth and cell development either within a tissue or between separate tissues. These hormones, about 10 in number (cf 50 in mammals) exert distinct transcriptional and translational leverage via characterised receptors. Growing plants are very sensitive to many characteristics of their environment; changes commonly initiate cytoplasmic $\mathrm{Ca}^{2+}$ transients similar in speed and length to those in mammals. Usually these transients precede subsequent hormone- initiated processes [1,2]. Additional control is implemented by intercellular and inter-organ movement of some proteins, mRNA's, sRNAs, peptides probably secreted in exosomal vesicles [3-5]. Some important minerals such as nitrate and phosphate have their availability assessed through characterised receptors and alter growth and development accordingly [6,7].

In 1956 Roger Williams published Biochemical Individuality [8], a book that compiled the ranges of some anatomical, biochemical and hormonal variations in normal healthy, reproducing human beings; basically their inter-individuality. As a Biochemistry UG, I was given it to read. But how I thought could all these individuals function, particularly those on the outer end of the published ranges. What I was taught didn't indicate variation; reductionism, exactness and chemistry was then king. Only with the later development of systems (network) biology could a better understanding emerge [9]. Systems used feedback and the behaviour of the whole was an emergent property that accepted variation in the lower levels; that was one explanation. Systems or network approaches to endocrinology are very recent [10] and perhaps need expansion. Interactions between hormones are known to occur and construction of a network with known strengths of interactions in defined conditions should improve both physiological and medicinal application.

Individual plants rarely, if ever, get mentioned in plant hormone studies (unlike those in medicine). Investigations simply averaged results from 10, 15 or 20 plants or more often plant tissues. Mechanisms were then deduced from the average. If one thing was clear from Williams [8], (and from Weiss [11]), the average probably didn't exist. Results always presented statistics (SD or SE) which disguises variation (in my view) and eliminated concerns that potential variation in mechanism was a problem. And if some individuals failed to respond at all, they too were rendered invisible. All this was complicated by good evidence that some if not all plant tissues are mosaics with apparently anatomicallyidentical cells responding differently to each other $[12,13]$.
Equally concerning was the largely ignored but potent influence of experimental conditions between different laboratories. Enormous difficulties were found in getting reproducible results between 10 different laboratories using identical inbred seeds with "apparently identical" experimental conditions [14]. Plants are superlatively sensitive to slight environmental variation. How much uncertainty they have contributed in the past in hundreds of publications is simply not known but it won't be small.

But were any of these experimental conditions relevant to the real world? Commercial interest invested heavily in basic plant hormone research in the late $50 \mathrm{~s}$ for agriculture but pulled out in the early $70 \mathrm{~s}$ when lab results failed to transfer to the field! This problem remains unresolved.

A detailed search of the literature turned up only three elderly papers reporting an inter-individual variation of 10,20 and 30 fold in two plant hormones [1]. So, a circuitous method that could suggest more general inter-individuality in plant hormone content was employed. (1). Phenotypic range (overall and organ sizes) and interindividual hormone ranges of human beings were tabulated. (2). Phenotypic range and inter-individual developmental variation (related to hormone activity) in one plant species (Arabidopsis) were tabulated. (3). Molecular variation, single nucleotide polymorphisms (SNP), epigenomic variation, splicing, copy number variants, molecular noise and somatic mosaicism were summarised for both plant and mankind. Variation in Arabidopsis was very much higher; for example SNPs were 1 in 10 for Arabidopsis but 1 in 80 for mankind. Since hormone synthesis will in part have a direct genetic basis this degree of variation is suggestive.

In early research, plant hormone bioassays were routine. Virtually all of these shared a characteristic feature, the biological effect could be detected over three, sometimes four, occasionally five and six orders of magnitude change in concentration in a log/linear relation [12]. When receptors for some of the primary hormones (auxin, gibberellin) were isolated however, typical simple binding curves of less than two orders of magnitude were reported with a midpoint $\mathrm{K}_{\mathrm{D}}$ about $10^{-7} \mathrm{M}$ and also about the endogenous working concentration.

All plant hormones so far examined and phytochrome, (a major light receptor controlling growth) use negative regulation. When the hormone binds to its receptor, this increases the affinity of the bound receptor to one or two other proteins. That final complex initiates the response which is commonly transcriptional. At the same time this

${ }^{\star}$ Correspondence to: Tony Trewavas FRS, Institute of Molecular Plant Science, Kings Buildings, University of Edinburgh, Edinburgh EH9 3JH, Scotland, E-mail: Trewavas@ed.ac.uk

Received: July 26, 2020; Accepted: August 03, 2020; Published: August 06, 2020 
active complex is targeted to endocytosis via ubiquitin ligase and the $25 \mathrm{~S}$ proteasome leading to its degradation.

Why does this happen? The processes of cell and tissue development are restricted in both space and time; receptors (and hormones) are synthesised when needed and degradation helps close the developmental window. The two-stage process with the second stage of higher affinity suggests that the Strickland/ Loeb model [15] could operate here. In this model, the sensitivity range of hormone operation is actually defined by the receptor level. That in itself suggests interindividual hormone variation is likely routine.

Clarity in plant hormone action would come from investigations of inter-individual differences. In only one paper has this been done, unfortunately it has been largely ignored and is hardly referenced at all [16]. By using many hundreds of experimental tissues for each set of measurements, histograms of the variable responses (including some null responses) between individuals to hormone treatment were reported. From information in the previous paragraph that might suggest variable receptor levels between individuals.

Compiling this information with that previously published [13] enables an explanation of why dose- response curves can be wider than expected. In situations when this happens the tissue under investigation is a mosaic; it contains cells that have reached the developmental window and can respond fully to a hormone stimulus. But likewise it contains cells that have not yet entered the developmental programme but have commenced their approach to it. And the approach involves increasing cellular receptor synthesis. Using much higher hormone levels than would ever be experienced, drives these 'immature' cells into the developmental window by compensating for their relatively low receptor concentration. The approach to a developmental window is thus not cell-synchronous. When cells leave the window, this too will be asynchronous. Is this simply acceptable variation from network interactions or are there discrete phases (windows) of growth and development in different tissues with asynchronous cell approaches? Is this molecular noise or a consequence of having some critical cell proteins in single figures? Answers are needed.

\section{What relevance has this to endocrinology?}

The tabulation of inter-individual human hormone variation indicated that human growth hormone (HGH) recorded the greatest variation, over 30 fold [1]. And also HGH together with its receptor is negatively regulated [17]. The combination with other proteins targets the complex to rapid ubiquitin-dependent endocytosis and proteasome degradation. The consequence is that $\mathrm{HGH}$ influence on growth will be receptor-specified rather than simply hormone concentration. Other insulin-like growth factors also exhibit very substantial inter-individual variation of up to 30 fold [1]. Are these the result of negative regulation again? Perhaps more important is the implication that human dwarfs commonly associated with growth hormone deficiency might instead be a receptor deficiency and treatment adjusted to take account of this possibility. Monitoring human hormone levels is a common medical exercise. Might it not be more important to acquire measurement of their receptor levels? Present technology makes this possible.

\section{Relevance to plant hormones}

It is not uncommon to find models of plant development which define cellular characteristics and change as the result of discrete concentrations and changes in concentration of hormone levels as process controllers. The collated inter-individual variations in developmental and growth processes [1] make these hypotheses difficult to justify in the absence of individual measurement of hormone concentration. Furthermore, if such models are to be used, how well controlled are hormone concentrations under real world circumstances? Technology is available to answer these simple but necessary questions. Experimental conditions are all very well but as pointed out above, commercial interest in plant hormones disappeared because experimental conditions failed to transfer to the field. If plant hormonology is to be a value to agriculture then experiments in real world circumstances are essential.

Plants and animals may be far apart in evolutionary terms but a similar mechanism for controlling growth between both groups suggests that one can learn much from the other about control of growth and development.

\section{References}

1. Watahiki M, Trewavas AJ (2018) Systems, Variation, Individuality and Plant Hormones. Prog Biophys Mol Biol 146: 3-22. [Crossref]

2. Gilroy S, Trewavas AJ (2001) Signal processing and transduction in plant cells: the end of the beginning. Nature Rev. Cell Biol 2: 307-314. [Crossref]

3. Kim JY (2005) Regulation of short-distance transport of RNA and protein. Curr Opinion Plant Biol 8: 45-52. [Crossref]

4. Brant EJ, Budak H (2018) Plant small non-coding RNAs and their roles in biotic stresses. Front Plant Sci 9: 1038. [Crossref]

5. Kehr J, Kragler F (2018) Long distance RNA movement. New Phytol 218: 29-40. [Crossref]

6. Gojon A, Krouk G, Perrine-Walker F, Laugier E (2011) Nitrate transceptor(s) in plants $J$ Exptl Bot 62: 2299-2308. [Crossref]

7. Rouached H, Arpat AB, Poirier Y (2010) Regulation of phosphate starvation responses in plants: signaling players and cross-talks. Mol Plant 3: 288-299. [Crossref]

8. Williams R (1956) Biochemical Individuality. Wiley \& Sons, New York.

9. Trewavas AJ (2006) A brief history of systems biology. Plant Cell 18: 2420-2430. [Crossref]

10. Stevens A, Leonibus C De, Handson D, owsey AW, Whatmore A, et al. (2014) Network analysis: anew approach to study endocrine disorders. $J$ Mol Endocrinol 52 R79-R93. [Crossref]

11. Weiss P (1973) The Science of Life: The Living System--A System for Living. New York.

12. Bradford K, Trewavas AJ (1994) Sensitivity thresholds and variable time scales in plant hormone action. Plant Physiol 105: 1029-1036. [Crossref]

13. Trewavas AJ Plants (2012) Information and noise in communication: thresholds as controlling elements in development. In Witzany C, Baluska F (Eds) Biocommunication of Plants 14: 11-35.

14. Massonet C, Vile D, Fabre J, Hannah MA, Caldana C, et al. (2010) Probing the reproducibility of leaf growth and molecular phenotypes: a comparison of three Arabidospsis accessions cultivated in ten laboratories. Plant Physiol 152: 4142-4157. [Crossref]

15. Strickland S, Loeb JN (1981) Obligatory separation of hormone binding and biological response curves in systems dependent upon secondary mediators of hormone action. Proc Nat Acad Sci USA 78: 1366-1370. [Crossref]

16. Liptay A, Davidson D (1971) Coleoptile growth: variation in elongation patterns of individual coleoptiles. Ann Bot 35: 991-1002.

17. Flores-Moraeles A, Greenhaigh C, Norstedt G (2006) Rico-Bautista, E. Negative regulation of growth hormone receptor signalling. Mol Endocrinol 20: 241-253. [Crossref]

Copyright: (C2020 Trewavas T. This is an open-access article distributed under the terms of the Creative Commons Attribution License, which permits unrestricted use, distribution, and reproduction in any medium, provided the original author and source are credited. 